\title{
Power distance and migrant nurses: The liminality of acculturation
}

\author{
Myung Suk Choi ${ }^{1}$ | Catherine Mary Cook ${ }^{2}$ | Margaret A. Brunton ${ }^{3}$
}

\author{
${ }^{1}$ MidCentral District Health Board, \\ Palmerston North, New Zealand \\ ${ }^{2}$ School of Nursing College of \\ Health, Massey University, Auckland, New \\ Zealand \\ ${ }^{3}$ School of Communication, Journalism and \\ Marketing, Massey University, Auckland, \\ New Zealand

\section{Correspondence} \\ Catherine Mary Cook, School of Nursing \\ College of Health, Massey University, \\ Private Bag 102 904, North Shore Mail \\ Centre Auckland 1311, New Zealand. \\ Email: c.m.cook@massey.ac.nz
}

\begin{abstract}
A dearth of literature focuses on the relationship between acculturation, power distance and liminality for migrant nurses entering foreign workplaces. Expectations are for migrant nurses to be practice-ready swiftly. However, this aspiration is naïve given the complex shifts that occur in deeply held cultural beliefs and practices and is dependent on an organisational climate of reciprocal willingness to adapt and learn. This exploratory study identified that although a plethora of literature addresses challenges migrant nurses face, there are limited data that link these transitional processes to concepts that might usefully guide transitions. This study draws from the overarching concept of acculturation, together with Hofstede's (2011) notion of power distance and the theory of liminality to explore the experiences of eight migrant nurses. Data highlighted that adjusting to altered hierarchical relationships took many months because negotiating power distance challenged deeply held beliefs and assumptions about professional and organisational hierarchies. Migrant nurses' accounts indicated a paucity of organisational processes to address these difficulties; therefore, they navigated this liminal space of adjustment to power distance differences in an ad hoc manner. Their acculturation experiences, arguably unnecessarily prolonged, indicate the value in workplace commitment to exploring a collaborative, critically reflective approach to optimise transitions.
\end{abstract}

\section{KEYWORDS}

acculturation, cultural diversity, intercultural communication, liminality, migrant nurses, power distance, preceptorship

\section{1 | INTRODUCTION}

With internationally qualified nurses (IQNs) constituting an ever-increasing proportion of the nursing workforce in developed countries, bridging programmes endeavour to enhance 'cultural fit' and readiness to practice in the new country (Khalili, Ramji, Mitchell, \& Raymond, 2015; Riden, Jacobs, \& Marshall, 2014; Sherwood \& Shaffer, 2014; Tie, Birks, \& Mills, 2018; Xu, 2010). However, research indicates that the transition process may extend well beyond an initial few weeks. It behoves managers, nurse leaders, educators, preceptors and mentors to be aware of the often lengthier process of accommodating differences that disrupt strongly held beliefs and values. Successful transition involves reciprocity, rather than being the unilateral responsibility of IQNs (Brunton \& Cook, 2018; Philip, Woodward-Kron, Manias, \& Noronha, 2019). Studies demonstrate that supportive leadership is a significant factor in transition and that leaders benefit from professional development to facilitate this process (Brunton \& Cook, 2018; Khalili et al., 2015; Ramji \& Etowa, 2018; Timilsina Bhandari, Xiao, \& Belan, 2014; Viken, Solum, \& Lyberg, 2018). The first author, who is an internationally qualified nurse, and currently a nurse educator, aimed to inform the role of educators and preceptors further by exploring challenges that a sample 
of Filipino and Indian culturally and linguistically diverse (CALD) nurses encountered when transitioning to the New Zealand nursing practice context. The New Zealand nursing workforce comprises of $25 \%$ of nurses who qualified outside of New Zealand, and in the past decade make up 50\% of all new registered nurse registrations (Nursing Council of New Zealand (2013)). Recent analysis indicates that $55 \%$ of migrant nurses come from the Philippines and $20 \%$ from India (Nursing Council of New Zealand, 2016). Host nurses are predominantly of European and British descent, with a small percentage of indigenous and Pacific nurses (for a fuller discussion on the role of internationally qualified nurses in the New Zealand context, see Jenkins \& Huntington, 2015).

A plethora of international literature highlights recurring themes in the adaptation process: workplace lack of skill-level recognition; communication barriers; differing assumptions about the role and tasks of registered nurses, and of patients and families; different values resulting in 'moral emotions'; racism; and discrimination and slow professional advancement (Cook \& Brunton, 2018; Tregunno, Peters, Campbell, \& Gordon, 2009; Tuttas, 2015). A comparative study investigating experiences of host and migrant nurses in the New Zealand context identifies that these processes of professional adaptation are disparate for these two groups (Brunton \& Cook, 2018; Cook \& Brunton, 2018). Adjustment to different dynamics in power relations and power distance is also reported across numerous studies. However, these accounts are explored with brevity (see, e.g., Philip et al., 2019; Xu, 2010; Viken et al., 2018) and there is a dearth of literature that focuses in depth on culturally and linguistically diverse (CALD) nurses' acculturation process in these areas. The rich data in the current study highlight familiar themes evident in the extant literature. Nurses' accounts of the disruptive effects of the transition process, which we argue pertain to power relations and power distance, were most striking across the data set. These differences were evident across all professional relationships: peerto-peer; nurse-senior nurse; nurse-student nurse; nurse-doctor; and nurse-patients and families. To address the gap in the literature, we apply the overarching theoretical concept of acculturation (Berry, 2005), and its relevance to power distance (Hofstede, 2011) and liminality (Willis \& Xiao, 2014) to deepen the analysis of the transitional discomforts experienced by IQNs, and to identify possible organisational and collegial steps that may ameliorate these challenges.

\section{ACCULTURATION}

As health professionals live and work in a rapidly globalising world, they inevitably encounter different cultures and worldviews. According to Hofstede (2011, p. 3), culture is 'a collective programming of the mind that distinguishes the members of one group or society from those of another'. Hence, a deep understanding of cultural values, beliefs and expressions is beneficial to co-ordinate organisational actions. Culture is a learned, collective phenomenon, at least partly shared with people who live or have lived within the same social environment. Culture remains 'below the threshold of conscious awareness because it involves taken-for-granted assumptions about how one should perceive, think, act, and feel' (Kreitner $\&$ Kinicki, 2007, p. 100). Every person carries patterns of thoughts, feelings and potential actions, typically acquired in early childhood. However, behaviour is only partially predetermined by mental programmes: people have a fundamental ability to deviate from longheld mental models and to react in ways which are new, creative, destructive and unexpected. However, unlearning is more difficult than learning for the first time (Xu, Gutierrez, \& Kim, 2008).

We concur with Garneau and Peplin's (2015) argument for a constructivist, rather than essentialist view of culture, which also acknowledges diversity within groups. Culture is not inherent to biological structure; rather it provides a frame of reference for identity and meaning. The relative 'sameness' satisfies the need for belonging within a comfort zone of inclusion, safety and acceptance. Culture is also symbolic, based on our capacity to use things to represent other things. Often achieved through language, for example, the use of shared narratives, songs, jokes and colloquialisms reinforces people's assessment of how embedded or not they are in a cultural group (Willis \& Xiao, 2014). People infuse words with emotional meaning, associated with shared norms and scripts. When one is an 'outsider', those norms and scripts may not be easily interpreted or understood (Zhou, Windsor, Theobald, \& Coyer, 2011). The camaraderie of culturally similar peers is significant in easing IQNs' acculturation process (Connor, 2016).

Acculturation is the process of change, to accommodate some aspects of another culture, ideally without erasure of normative values and practices of one's own culture. For example, Xu et al. (2008), in their small qualitative study of Chinese nurses who had migrated to the US, found that they continued to uphold their Confucian values of humility. Acculturation is impeded if IQNs experience limited career advancement and lack of recognition of prior abilities that they associate with discrimination and racism. Ramji and Etowa (2018) note that social closure, the exclusionary practices of majority groups that limit IQNs' professional advancement, leads to a persistent sense of being 'other' and therefore disrupts workplace integration. Acculturation at best involves reciprocity. As Berry (2009) argues, 'Acculturation is a process of cultural and psychological changes that involve various forms of mutual accommodation, leading to some longer-term psychological and sociocultural adaptations between both groups' (p. 699).

Acculturation is an overarching concept. Within the acculturation process, navigating power distance is a key challenge highlighted in the shift from a hierarchical to a more egalitarian context, and vice versa. Cultures are also adaptive, responsive to people's ability to accommodate their changing environment. Cultures tend to dictate what people learn about. They comprise group characteristics of behaviours, values and attitudes, which are mostly maintained and transferred to new members of the group. Hofstede argues that 'values have both intensity and direction' (1980, p. 19), and although cultures are complicated and full of ambiguity, they are powerful drivers of attitudes and behaviours. Tensions will be experienced through challenges to values and norms that are outside the cultural 
group. Receptivity towards adapting to the other is determined by the perceived salience and acceptance of any required changes.

\section{POWER DISTANCE}

Hofstede (2001) suggests that cultures can be distinguished by the cultural emphasis they assign to values and behaviours that promote normative dimensions across countries. He identified four cultural values in work-related attitudes relevant to political, social and individual interpretations, which reflect traditions and common ways of thinking. According to Hofstede, these dimensions are globally applicable, therefore comparable (Hofstede, 2001). These comprise the individualism/collectivism and masculinity/femininity dichotomies, and degrees of uncertainty avoidance, and power distance, the latter of which is relevant to the analysis in this article. Power distance refers to the extent to which individuals and groups have hierarchical or egalitarian relationships.

Power distance is the level of acceptance of an equal distribution of power relations in society, defined as 'the degree to which members of an organisation or society expect and agree that power should be stratified and concentrated at higher levels of an organisation or government' (House \& Javidan, 2004, p. 12). All societies have degrees of inequality, which Hofstede measured on a scale from high (100\%) to low (0\%). High power distance social values incorporate the recognition and acceptance of high power differentials between different members of a culture, society or organisation. In high power distance contexts, there is overall mutual agreement from members of that group that power inequalities are considered legitimate; thus in workplaces, supervisors are expected to be more autocratic and paternalistic. As Yan and Hunt (2005) argue, paternalism is viewed as advantageous. In contrast, those cultures, societies or organisations with less sensitivity to variations in status expect to share power through democratic leadership styles preferring a more consultative approach and emphasise the right to participate in all levels of decision-making. These contexts have low power distance as defined by Hofstede. In contexts with high power distance, there is limited social mobility, compared with high social mobility in low power distance contexts.

We acknowledge that Hofstede's work is subject to critique (see, e.g., McSweeney, 2002), especially given that his survey data were collected in the 1960s and 1970s. Other criticisms draw attention to diversity within cultures and countries; the problem of individual stereotyping based on group-level data; ignoring cultural heterogeneity within cultures; and the malleability of culture (Sivakumar \& Nakata, 2001; Smith, 2002). However, the model has also been validated by further research (Bochner \& Hesketh, 1994; Drogendijk \& Slangen, 2006; Van Oudenhoven, 2001). A further cohort analysis by Beugelsdijk, Maseland, and van Hoorn (2015) demonstrates that relative positions between countries in relation to Hofstede's dimensions have not altered over time. This finding concurs with Hofstede's argument that although power distance may change over time, the degree of difference between countries likely remains
(1991). More recent global studies have continued to confirm that New Zealand is a low power distance country, and the Philippines and India higher on the scale (Javidan, De Luque, Sully, \& House, 2006). Such differences may be of concern when acknowledging that unfair treatment from those in powerful organisational roles may be more accepted in high power distance cultures, while those in low power distance cultures are less accepting of injustice (Loh, Restubog, \& Zagenczyk, 2010).

The status of nurses differs globally. A study by Johnson, Green, and Maben (2014) identifies that until recently nursing in India was a low status, menial, stigmatised job, as many aspects of the work contravene notions of purity and the traditional role of women, such as working outside of the home and engaging with strangers' bodily fluids. Due to migration opportunities, nursing has become a more valued profession (Timmons, Evans, \& Nair, 2016). Nurses from both the Philippines and India have identified that the high comparative status of New Zealand nurses, including the educational and advanced practice opportunities, was an influential factor in migration (Mowat \& Harr, 2018). In an integrative review, Montayre, Montayre, and Holroyd (2018) note nurses in the Philippines report a subservient relationship with medical colleagues, without an autonomous role.

Hofstede's work continues to have contemporary empirical utility in research pertaining to cultural diversity in healthcare. For example, in a small qualitative Australian study by Philip et al. (2019) their analysis identified that even though IQNs enjoyed the advantages of the very low power distance between nurses and doctors, it was a significant adjustment to speak collegially with medical staff. In a comparative study investigating clinical reasoning skills in an Australian and an Indonesian medical school, the findings illustrated that power distance differences were evident between participants at the two sites, thus playing a significant part in the students' different attitudes to authority, which impacted on uncertainty avoidance (Findyartini, Hawthorne, McColl, \& Chiavaroli, 2016). A UK study by Morrow, Rothwell, Burford and Illing (2013) used the concept of power distance to portray that status and hierarchy were the most challenging area to navigate for new migrant doctors from high power distance countries across all professional relationships. In another UK study, researchers identified high power distance was evident in the ways international medical graduates engaged with simulated patients, compared to their UK educated counterparts (Verma, Griffin, Dacre, \& Elder, 2016). While appreciating the limitations of concepts and frameworks, we argue that they also provide a useful beginning point for critical reflection.

\section{4 | LIMINALITY}

To bring together an investigation of acculturation to shifts in power distance, the anthropological concept of liminality is used. This concept captures the period of ambiguity and uncertainty in substantive shifts from one role or status to another. We concur with Willis and Xiao (2014) that the lens of liminality usefully renders visible 
the transformative process IQNs undergo as they encounter the hardship, fear of failure, and disruption of their previous status. Importantly, liminality is not a linear process; intrinsic and extrinsic factors may mean that nurses may remain in a liminal space if they are excluded and stigmatised.

\section{5 | STUDY DESIGN}

As an exploratory study, this research draws from an interpretive phenomenological approach (de Chesnay, 2014) to capture reflexive explanations of the lived experience of a sample of IQNs in a cultural and workplace environment that was unfamiliar. With an interpretive phenomenological approach, the researchers endeavour to interpret participants' sensemaking, while ensuring their interpretations are grounded in participants' accounts (Pringle, Drummond, McLafferty, \& Hendry, 2011).

\section{6 | PARTICIPANTS AND SETTING}

After obtaining ethics approval (4000017380) from a university human ethics committee, recruitment occurred mid-2017. Participants were recruited from one provincial District Health Board hospital. Flyers were placed in nursing offices, and potential participants made contact by email or phone with the first author. A full information sheet was then provided, and on confirmation of the decision to proceed, interviews were arranged. Although the first author is an IQN, she is Korean, and therefore had an insider/ outsider position (Liamputtong, 2010), as although there were many similarities in experiences, she was not familiar with the cultural specifics of any of the participants. The first author used a process of reflexivity throughout the data collection process, including regular discussions with the second author, to ensure that her own lived experiences were not to the fore in the interview process (Liamputtong, 2009).

\section{7 | DATA COLLECTION AND ANALYSIS}

The study involved eight semi-structured interviews, conducted in English, with a purposive sample (Abrams, 2010) of IQNs who obtained their initial nursing registration overseas and then completed their nursing transition through a CAP course in New Zealand; had not worked in other countries as an IQN; had been working as a registered nurse in New Zealand for less than five years; and for whom English was their second language. There were four females (3 Indian; 1 Filipina) and four males (2 Indian; 2 Filipino); ages ranged from 28 to 34 years. Respondents averaged 3 years of practice in their home country, sharing on average 4 years of overall experience since registration as an IQN. All worked in an acute hospital setting. These interviews occurred in a private setting after having obtained informed consent.
The interview questions were focused on eliciting detailed descriptions of IQN's experiences of learning how to adapt to the new workplace culture. The interview schedule was developed from a review of the literature that explored the following broad question: What are the cultural, educational and linguistic challenges for CALD nurses transitioning to registered nursing practice in New Zealand? Examples of the open-ended questions are as follows: Could you tell me any cultural differences you had faced during the initial Competence Assessment Programme? Could you tell me about any differences in the nursing position in your own your home country compared with New Zealand? Could you tell me about the interpersonal relationship among nurses, other health providers, patients and their families in your workplace? and Could you tell me any cultural differences in your workplace? Each interview lasted for between 45 and $60 \mathrm{~min}$. The data were read by the researchers and coded for common threads of meaning.

\section{8 | POWER DISTANCE AND ACCULTURATION}

Through the interviews, we gained an understanding of the experiences of each participant to provide insight into the acculturation process for IQNs. The data set clearly demonstrates the considerable acculturation work for IQNS, and in our analysis, the effort of transition was in part because expectations and experiences of power relations were destabilised across all professional relationships. These disruptions to beliefs about status and authority appeared to add significantly to the emotional and cognitive load of acculturation. These disruptions were evident across four domains that are elucidated further below: un/learning and the 'hidden curriculum'; destabilisation of expertise; preceptors and leaders as navigators; and finding one's voice. Table 1 shows the categories, codes and exemplar quotes to illustrate how we arrived at our themes.

\subsection{Un/learning and the 'hidden curriculum'}

Clearly evident across the data set was the struggle that participants experienced, to engage with an alien educational process. In order to register in New Zealand, IQNs must complete a six-week theory and practice Competence Assessment Programme (CAP). These programmes are offered collaboratively by tertiary and healthcare service providers, with the aim of ensuring nurses are able to meet competencies within their scope of practice (Nursing Council of New Zealand n.d.). All were familiar with a teacher-driven approach, and the shift to teaching informed by more egalitarian adult learning principles was yet another adjustment. Students expressed the discomfort and doubts they had about the effectiveness of learnercentred approaches:

Here, you have to paraphrase and provide all the references and avoid the plagiarism and the system shows you how much your assignment is similar to the 
TABLE 1 Exemplar themes

\begin{tabular}{|c|c|c|}
\hline Categories & Codes & Exemplar quotes \\
\hline $\begin{array}{l}\text { Un/learn- } \\
\text { ing and the } \\
\text { 'hidden } \\
\text { curriculum' }\end{array}$ & $\begin{array}{l}\text { Strangeness } \\
\text { Rote learning } \\
\text { Learner-centred } \\
\text { approaches } \\
\text { Critical thinking } \\
\text { Dis/empowerment }\end{array}$ & $\begin{array}{l}\text { They do as self-directed learning but I am not quite sure how much the students get the knowledge } \\
\text { from the self-directed learning. Back home, we really go through every topic thoroughly and do the } \\
\text { exams so we can get tested and get the knowledge from the text books. So we have to study thor- } \\
\text { oughly for the examinations. I think they learn very broadly here but not quite sure how deep they } \\
\text { learn to get the academic knowledge. (Participant } 5 \text { Indian) } \\
\text { But here, you have to paraphrase and provide all the references and avoid the plagiarism and the } \\
\text { system shows you how much your assignment is similar to the references. It is a really self-directed } \\
\text { learning so you study yourself spending enough time and all your responsibilities will be on you. } \\
\text { Because I came from the entirely different practice for years so everything was extremely hard for } \\
\text { me. So you can only get limited knowledge that you study here. But I feel the Indian style study is } \\
\text { more helpful. I get more knowledge than the teaching style here. (Participant } 2 \text { Indian) }\end{array}$ \\
\hline $\begin{array}{l}\text { Destabilisation } \\
\text { of expertise }\end{array}$ & $\begin{array}{l}\text { 'Othering' } \\
\text { Sense of loss } \\
\text { Disruption } \\
\text { Criticism } \\
\text { Apprehension }\end{array}$ & $\begin{array}{l}\text { As a foreigner, I think I am very lucky to get a job here. You know, we have got a visa issue so some- } \\
\text { times, it is very hard to say no to others, especially to my charge nurse and I try to not to say no and } \\
\text { just try to be good even when I face something unexpected or unfair things until my status is stable. I } \\
\text { don't want to have any negative feedback from my managers. But Kiwis,.they just speak up and stand } \\
\text { up when they feel unfair [behaviour] from other people. (Participant } 6 \text { Indian) } \\
\text { We work together for the best outcomes for the patients. I want to get respect from others as I } \\
\text { respect others and we are supposed to have respect too. That is why I can say working here is beauti- } \\
\text { ful... When duty nurse managers have a round...they are really happy and pleasant when they to talk } \\
\text { with us but I still have the huge gap and uncomfortable feeling from deep in my mind. (Participant } 7 \\
\text { Indian) }\end{array}$ \\
\hline $\begin{array}{l}\text { Preceptors and } \\
\text { leaders as } \\
\text { navigators }\end{array}$ & $\begin{array}{l}\text { Bridges } \\
\text { Barriers } \\
\text { Sameness } \\
\text { Inclusion } \\
\text { Exclusion } \\
\text { Mentoring }\end{array}$ & $\begin{array}{l}\text { I think Kiwi [New Zealand] students' attitudes are very different. We, as a student, never sit down and } \\
\text { have a chat with other people. Here, students don't have any responsibility. They only do what you } \\
\text { tell them to do. Every single thing, we need to supervise them and direct them. (Participant } 8 \text { Indian) } \\
\text { She knew that most of the international nurses would not react and speak up even though we are } \\
\text { treated unfairly. She knew that we will be silent. I felt that from her talk and it is not only my feeling. } \\
\text { When one nurse left for her leave for three months, she gave me all night shifts for the three months. } \\
\text { Do I deserve to have all the night shift? No. I also have a right to work other shifts. It is very unfair. } \\
\text { (Participant } 7 \text { Indian) }\end{array}$ \\
\hline $\begin{array}{l}\text { Finding one's } \\
\text { voice }\end{array}$ & $\begin{array}{l}\text { Hierarchy } \\
\text { Sensitivity } \\
\text { Status } \\
\text { Authority } \\
\text { Questioning }\end{array}$ & $\begin{array}{l}\text { Over there, back home, if doctors say you do this, you have to do it. The doctors have the power to } \\
\text { tell you to do it. Even though it is not right, you will do it. There is no questioning about medications } \\
\text { or dosage. No negotiation at all. But here, you find something wrong, you will say to the doctors and } \\
\text { discuss. (Participant } 8 \text { Indian) } \\
\text { We never prioritise patients' choices back home. But here, we really respect their decisions and ask } \\
\text { their permissions and preferences even for a cup of tea. (Participant } 6 \text { Indian) }\end{array}$ \\
\hline
\end{tabular}

references. It is a really self-directed learning so you study yourself spending enough time and all your responsibilities will be on you. Because I came from the entirely different practice for years so everything was extremely hard for me. So you can only get limited knowledge when you study here. But I feel the Indian style study is more helpful. I get more knowledge than the teaching style here.

\section{(Participant 2 Indian)}

Analysis indicated unfamiliar power distance between the learner and the teacher, which appeared to have been experienced initially as an additional stress, rather than liberating. A participant identified that he struggled with being given responsibility for his own learning, rather than the educator being the authority:

Here, they let you study yourself giving materials, but back home, they force you to do it. In the process, you will learn it, personally, it is better for me. We can have a clear deadline for example so you have to finish the task before the deadline. But here, all the study - I need to set up the goal and deadline usually. It takes a very long time to finish because no-one pushes me and everything is on me. If you have a deadline coming and my instructor really wants you to do it, it can be a very strong motivation for you to complete.

(Participant 1 Filipino)

In our critique, it was evident that for all participants, the initial Competence Assessment Programme was an exhausting process. Data analysis highlights not only were they engaging with explicit, formal content, they were also navigating the 'hidden curriculum' of an unfamiliar set of beliefs and values about what it means to be a learner. This concept of the hidden curriculum refers to the often tacit or unarticulated assumptions, beliefs and values within organisational structures that maintain existing norms (Hunter \& Cook, 2018; Mossop, Dennick, Hammond, \& Robbé, 2013). This is an important tension to note, as notions of empowerment underpin adult learning theories, but the shift to the inherent low power distance of these approaches can disempower learners if they are 
not adequately supported through this transition. In our analysis, these educational discomforts are also examples of migrant nurses as learners in a liminal space, as the teaching practices do not align with past experiences and therefore increase uncertainty and fear of failure. Philip, Manias, and Woodward-Kron (2015) appear to affirm uncritically the 'learning partnership' model provided by Australian nurse educators in a pre-registration bridging programme. There is little acknowledgement of the stress for learners engaging in new pedagogies and the concomitant shift in power distance between educators and students. Although power distance is discussed, the focus is on IQNs transforming rather than a mutual transformative process. By contrast, Wang and Greenwood (2015) argue that educators need to be responsive to and respectful of different ways of learning. They call for a 'culturally sensitive pedagogy' (p. 257) that involves educators in a reciprocal willingness to adapt and learn. For example, educators may need to introduce activities such as discussions and group activities slowly, with ample guidance and preparatory time.

\section{2 | Destabilisation of expertise}

Participants described the initial orientation period as an uneven process, where some of their authority and expertise no longer had a place, and therefore, they experienced receding status. We argue that this finding illustrates that in some instances, participants experienced greater power distance than they were familiar with when working with medical colleagues; it was not always a case of adjusting to lower power distance. A participant from the Philippines expressed surprise at the loss of her prescribing skills:

Back home, as a nurse, we had to prescribe, it is actually different from here, not allowed prescribing, back home we are the ones who write prescriptions and having the doctors just for countersign.

$$
\text { (Participant } 3 \text { Filipina) }
$$

An Indian IQN also expressed frustration at his inability to use his skill set:

When you become an RN in India, you can do all cannulation, suturing, intubations and many other things, based on your experiences, you can do whatever you can... But in New Zealand, everything, you go through step-by-step and you have a study day and get the experience and being assessed by other nurses. I think nurses in NZ have a lot of limitations than India... I like to be autonomous but many limitations here annoy me too.

$$
\text { (Participant } 5 \text { Indian) }
$$

The delivery of patient care was another area of unfamiliarity to be navigated that left nurses unable to draw from their previous role confidence in their home countries. A participant highlighted that teamwork processes were significantly different due to the role of families and workload management:

In the Philippines, there are many family members and relatives staying with patients overnight so they look after their family but here, family members just visit them and let the nurses do the cares. Back home, we are used to the functional nursing so it is like that one nurse does the medications and obs [observations] while the other nurse takes doctor's orders.

$$
\text { (Participant } 4 \text { Filipino) }
$$

A nurse from India also faced adjustments in the shift to a different model of care:

But here, nurses deal with a lot of social issues, personal hygiene and you do everything from $A$ to $Z$ for your patients. You are the one who does everything and has a lot of responsibilities. You do all the comprehensive and holistic care for your patients and their family. It really surprised me and it was something I needed to step up to. Everything was questionable.

(Participant 2 Indian)

A nurse from India spoke of the major adjustments she had to make in terms of her status as a registered nurse, as she has had to engage in activities that she has not previously seen as the domain of the registered nurse; that they are either beneath or above her role. These experiences were deeply unsettling as they disrupted her long-standing assumptions about her authority and responsibilities:

Most of the jobs [at home] are done by students. In the wards, family members do many things, almost everything for them like feeding, mobility, washing, and toileting. But here, we do everything. We need to do a cleaner's job; care assistants' jobs; doctors' jobs; nurses' jobs and we do everything. If you need a cleaner to clean a dirty toilet, if they are not coming now, you need to do it, don't you? If we don't have any care assistant, you need to do all the patients' hygiene, bed making and deliver meals and cups of tea... We don't have any option here. If you don't get any support, you have to do it. But back home, we have options. You can say to someone, "you do this, you do that and I will do this." But here, everything is your job.

(Participant 8 India)

The above quotes illustrate that the IQNs experienced a loss of status in their sense of what it means to be a nurse as they navigated significant shifts in power distance expectations. We consider that this description further highlights the discomforts and disruptiveness in 
navigating the liminal space, as professional identity was called into question by these nurses. They had to give up undertaking some skills, and to take on engaging in work that in their home countries was delegated to workers and families members whose roles were seen to be of lower status.

Language issues also undermined their sense of professional credibility with patients and their families. The disempowering confusion about colloquial terms was reported by all participants. This difficulty navigating everyday conversations appeared to contribute to what we argue is a liminal space, where nurses were unable to embody fully a sense of professional identity in the new context. A participant from India gave an example of how one colloquial word can lead to a prolonged and distressing interaction:

I looked after one lady who was blind but was very strict about every single thing around her. She was one of the hardest patients I have had. One day she said, "I want my spencer [long-sleeved vest] from that drawer." I didn't know what a spencer is. She was getting very angry at me because I could not understand her. I opened the drawer but I could not figure out what she wants. So I came out and asked another person to figure out what she wants. I hadn't heard that word before... Because I don't know many words here, it can make me very uncomfortable and withdraw. I think the language barrier is the biggest problem for us.

(Participant 8 India)

All participants gave examples of where they had yet to overcome communication challenges with families, such as the ability to exchange everyday chat that undermined their confidence. In the following example, the participant expressed distress that the student's communicative confidence usurped his authority:

Some of the nursing students are really talkative and have chats with patients and their families very well. They have very good communications each other rather than with me as a nurse. So the patients may be very attached to the student than me. Sometimes I feel it is difficult and sometimes I think "am I a nursing student or she is the student?"

(Participant 5 Indian)

We consider that these examples illustrate the complexities of acculturation, power distance and disorientation of the liminal process. These concepts are useful to make sense of nurses' discomforts and identity disruption. The rigours of shifting from individual experiences of high power distance to low power distance warrant visibility. Zhou et al. (2011), in an Australian qualitative study involving 28 China-educated nurses, also noted acculturation challenges, as they perceived that differences were often interpreted by host nurses as signs of incompetence. When differences were noted, the IQNs perceived that their nursing practice was automatically considered deviant, and therefore not permissible. These practices widen the power distance between IQNs and host nurses.

\section{3 | Preceptors and leaders as navigators}

The quality of preceptorship made a lasting impression on all participants. Data analysis indicated that it was through this relationship that migrant nurses learnt to navigate different power relations. In the following quote, the nurse described the problematic issue she encountered as although healthcare assistants were subordinate to her, they were much older than her, which created a dilemma as to how to respond:

Some old caregivers who have a long experience didn't listen to nurses. We told them something to do but they won't listen to but they will do their own way. Several times this had happened and my preceptor told me that you have to be stronger because they know that that is your weak points. They knew that most Asian nurses are very gentle, young and new here. They were here for a long time and they have got experienced and know more than you in the perspective view of caregiver though. It was really hard to manage in the rest home.

(Participant 7 Indian)

The same Indian participant described her strong, embodied response to wide differentials in privilege and status associated with hierarchy, position and formal authority. We contend that she continued to enact the power distance behaviours that were familiar to her:

When my manager and charge nurses come to me, automatically I become frozen and stand up. No matter how busy you are or how many work you have to do, you have to stop and stand up [in India]. Before I realize that I am here in New Zealand, my body just automatically responds like that. One of the managers asked me, "Why are you standing up? Just sit down and do your work. Don't worry about me." When we do a handover here, doctors and other people need to wait until the handover finish. Back in India, if you are in the same handover or if you are in the middle of doing something with your patients, you have to stop and go with them.

(Participant 7 Indian)

Participants indicated that preceptors and leaders have a significant role in coaching migrant nurses to manage unfamiliar communication exchanges, taking into account cultural beliefs about status, authority and power in the workplace. A nurse from the Philippines also commented on the disempowering impact of unfamiliar care routines, especially when paired with unsupportive preceptorship: 
I was bullied by the preceptor. Actually when I first started, I had no idea, the orientation was supposed to be just for her to show me how she works in a shift or in a day but the orientation with me was really different because she told me to plan my care, she just told me, "plan your care and I will come back." and I had no idea what to do. Then she asked me when she came back "so what are you doing to do now?" ... I found that she had high expectations of me and she thinks I am already trained and experienced so she wasn't really as helpful as...you know... teaching me this step by step process and how she does her shift. I thought preceptors should be very welcoming, showing you how they do nursing care in a shift or in the hospital...like a teacher, like a good example. Back in Philippines, we have clinical instructors, similar to a preceptor, they don't have any patients in the ward but always focus on us and oversee our work and discuss with us during our clinical practice.

(Participant 3 Filipina)

This participant had expected that her preceptor would use her position of authority to protect and mentor her, as she had experienced in her home country. Instead, the facilitation of the acculturation process through fair procedures and informed leadership was missing.

These examples show some of the struggles of working in an organisational culture imbued with low power distance characteristics, as the IQNs wanted leaders to show leadership and to give guidance. Friendliness shown by preceptors made it possible for IQNs to expose vulnerability. Riden et al.'s (2014) survey of 151 preceptors of IQNs in New Zealand drew attention to preceptors' frustrations at their limited preparedness for this role, and the lack of recognition and workload adjustment. They considered that generic preceptorship courses were inadequate for successfully preceptoring IQNs.

\section{4 | Finding one's voice}

The relatively low power distance between members of the multidisciplinary team, including students and healthcare assistants, required considerable adjustment and at times discomforted IQNs. All participants highlighted that in their home countries, the gap in authority between medical and nursing colleagues was significant to the point that nurses were categorically subordinate. A nurse from the Philippines explained the medical power he was familiar with that led to nurses not speaking up:

In terms of the relationship between nurses and doctors, doctors are the ones who are superior - you don't stand up to doctors. Back home, doctors run hospitals, I mean they are the owners of the hospitals and many directors and managements are doctors.
For example, if there are any problems, doctors showing bad attitudes towards nurses, nurses really cannot speak up but just suck it up. If nurses complain against doctors, they can be fired by doctors. It is a strong hierarchy.

(Participant 4 Filipino)

The above participant reported enjoying a newfound level of autonomy, and equity with medical colleagues:

There is a high level of accountability. You should be accountable for your patients and you should follow the policies and protocols. You have an equity with doctors and more autonomous. So, I am really satisfied being a nursing so far in New Zealand.

(Participant 4 Filipino)

We interpret the above quote as an example of a migrant nurse successfully accommodating change and emerging out of a liminal space as he incorporated accountability into his professional identity. All participants at the time of interview were enthusiastic about the relative egalitarianism they experienced, even though finding their voice was a journey, as illustrated in Table 1. An Indian IQN expressed how her migrant status, including visa uncertainties, combined with cultural behaviours in making it hard for her to speak up and complain:

As a foreigner, I think I am very lucky to get a job here. You know, we have got a visa issue so sometimes, it is very hard to say no to others, especially to my charge nurse and I try to not to say no and just try to be good even when I face something unexpected or unfair things until my status is stable. I don't want to have any negative feedback from my managers. But Kiwis, they just speak up and stand up when they feel unfair [behaviour] from other people.

(Participant 6 Indian)

This participant's explanation exposes the complexities in not speaking up. Power distance only partially accounts for her silence; her perceived vulnerability as a new migrant with an insecure visa status also contributed. Our analysis is that uncertainties surrounding visa and residency status contribute to liminality, as the nurse did not perceive she had the full entitlements that other nurses had.

All participants spoke of the challenges now they were preceptoring students. An Indian IQN described her discomfort with the limited authority she perceived she encountered in the relationship between student nurses and registered staff. She found the attitude of students perplexing and discomforting because as a preceptor she had to speak up repeatedly, and state what appeared obvious to her: 
I think Kiwi [New Zealand] students' attitudes are very different. When I was a nursing student, we are very ready to do something, like stand by for something. We, as a student, never sit down and have a chat with other people. We had a lot of work like helping patients' washes for full-assist patients. That job was actually done by the first year nursing students. These kinds of basic nursing like hygiene care and bed-making things are very important tasks for the student otherwise they will be told off by their lecturers and should be finished before you go to your class. Here, students don't have any responsibility. They only do what you tell them to do. Every single thing, we need to supervise them and direct them. When patients' call bell is ringing, they don't go until we ask them, "can you please go and check why the patient presses the bell?"

(Participant 8 India)

The adjustment to new 'rules' about deference and respect took conscious effort to manage as so many subtle assumptions about authority did not apply in the new work environment. Xu et al. (2008) also noted frustrations with the work ethic of subordinates, some of whom appeared to treat them as if they had less authority than host nurses.

\section{9 | PRACTICE IMPLICATIONS}

These data vividly demonstrate the acculturation process IQNs navigated, with the liminal discomforts and the obvious and subtle adjustments to power distance, due to differing beliefs, values and organisational culture. We argue that it is significant that this topic has not been rigorously explored previously in nursing, as it is clear even in this small sample study that there are practice implications for IQNs, host colleagues and organisations. An awareness of power distance challenges is significant content for educators, preceptors and nurse leaders to incorporate into transition and orientation programmes and initial placements. Hardcastle $(2018,148)$ calls for 'an informed and deliberate training programme' to support these nurses, who play a crucial role in service delivery.

Analysis of the data set in the current study illustrates that participants experienced the shift in power distance from teacher-led to student-centred learning as problematic and ineffective. The educators' efforts in the CAP programmes to facilitate the IQNs' autonomous critical thinking increased the feelings of discomfort associated with liminality. Similarly, in a comparative study of Australian and Indonesian medical students, Indonesian students' preference was to defer to the authority and receive directive guidance from teachers (Findyartini et al., 2016).

Our data indicate that the challenges of accommodating shifts in power distance extend well beyond the initial six-week CAP course. Lengthy transition processes were also noted by Xu et al. (2008), in their small study of Chinese nurses working in the U.S. context. Workplace comfort rather than mere survival was reported after a year, the length in part due to 'othering' practices of host colleagues, where migrant nurses were treated as 'less than' and were subject to stereotypical negative cultural biases. Xu (2010) recommends a preceptorship or mentorship process that lasts up to a year. We argue that the deliberate training must be a two-way process, and concur with Zhou et al. (2011), that difference is a socially constructed concept that warrants deconstruction by host and migrant nurses, to foster inclusivity.

Loss of familiarity and comfort with power distance expectations have also been highlighted in Morrow's, Rothwell, Burford, and Illing (2013) qualitative study of 66 UK new migrant doctors from high power distance countries. Participants in their study noted significant adjustments. For example, in their country of origin if they made mistakes, they were not challenged because 'you're a small God' (p. e1540), whereas in the UK errors were pointed out. They also noted that asking for help from senior colleagues was difficult to adjust to because in their homeland context, hierarchy meant there was a 'huge barrier' (p. e1540) to communication with senior colleagues. Participants also reported the adjustment to seeing nurses as colleagues with opinions rather than subordinates. Similar to findings in the current research, participants in Morrow et al.'s study were struck by the substantively different power relations between medical staff and patients. They particularly noticed the friendlier, more egalitarian decision-making that occurred, where doctors were more servants than masters. This shift impacted on everyday communication with patients, for example in relation to what for these participants was a new emphasis on informed consent. Verma et al.'s (2016) small-scale study also highlighted findings indicating that doctors from high power distance countries struggled to respond to patients who anticipated a more egalitarian relationship evidenced by inclusion in decision-making.

Transitioning through the liminal space involves departure from previous status assumptions; the in-between liminal phase where old power distance values no longer work but IQNs are not 'fluent' in new ways; and the emergence of experiencing oneself as having full membership in a group. This emergence does not mean giving up treasured beliefs and values. Rather, it is the ability and confidence to adapt and analyse consciously where to compromise and where foundational values will be adhered to. Successful transition through the liminal space is dependent not only on the efforts of individual IQNs but also to the preparedness and receptivity of host organisations and their staff.

Willis and Xiao (2014) point to three potential outcomes for IQNs: they may be permanently positioned as outsiders, and therefore remain trapped in the liminal space; they may shift to a hybrid space, one in which both host and migrants make accommodations to new ways of doing and being; or there may be a much more substantial shift on the part of host organisations and staff, away from automatic assumptions of the unquestionable superiority of all aspects of Westernised nursing. Kim (2010) also argues for a move away from assumptions of homogeneity in 'Asian' communication analyses, and 
a departure from an uncritical, one-sided Eurocentric standpoint that privileges Westernised communication styles and theories. In a systematic review, Viken et al. (2018) contend that IQNs need an extended orientation period with supported opportunities for guided reflection on practice to ensure patient safety. However, we concur with arguments that both host and IQN nurses need these opportunities to reflect together, to foster learning through openness and experimentation, in order for teams to function coherently (Brunton \& Cook, 2018; Cook \& Brunton, 2018). An appreciation of disparities in power difference and the practice implications need to be grasped by all team members.

\section{0 | CONCLUSION}

Expediting workplace integration of IQNs is a worthy goal both ethically and fiscally. This study demonstrates that acculturation, which includes navigating power distance and liminal uncertainties, is a significant and often lengthy process for IQNs. Practising differently challenges long-held beliefs, values and assumptions about organisational hierarchy and authority and also has implications for patient safety and well-being as nurses adjust to new expectations. Without clear organisational and collegial strategies, IQNs' tacit accommodation of shifts in power distance may disrupt professional identity and confidence for an unnecessarily extended time period. Collegiality, including role-modelling, assists in making this liminal period tolerable and comprehensible. The data highlight the need for reciprocity in the acculturation process to overcome the alienation felt by IQNs. Although there is a plethora of literature about the challenges for IQNs, few offer a useful beginning point for critical reflection, such as frameworks and concepts to optimise transition processes. It is of value for preceptors, managers, educators and migrant nurses themselves to understand the acculturation process, including the liminal process that is undergone when navigating shifts in power distance, in order to expedite a collaborative and critically reflective approach to optimising transitions.

\section{REFERENCES}

Abrams, L. (2010). Sampling 'hard to reach' populations in qualitative research: The case of incarcerated youth. Qualitative Social Work, 9(4), 536-550. https://doi.org/10.1177/1473325010367821

Berry, J. W. (2005). Acculturation: Living successfully in two cultures. International Journal of Intercultural Relations, 29(6), 697-712. https:// doi.org/10.1016/j.ijintrel.2005.07.013

Berry, J. W. (2009). A critique of critical acculturation. International Journal of Intercultural Relations, 33(5), 361-371. https://doi.org/10.1016/j. ijintrel.2009.06.003

Beugelsdijk, S., Maseland, R., \& van Hoorn, A. (2015). Are scores on Hofstede's dimensions of national culture stable over time? A cohort analysis. Global Strategy Journal, 5(3), 223-240. https://doi. org/10.1002/gsj.1098

Bochner, S., \& Hesketh, B. (1994). Power distance, individualism/collectivism, and job-related attitudes in a culturally diverse work group. Journal of Cross-Cultural Psychology, 25, 233-257. https://doi. org/10.1177/0022022194252005

Brunton, M., \& Cook, C. (2018). Dis/Integrating cultural difference in practice and communication: A qualitative study of Registered Nurse perspectives from the clinical interface. International Journal of Nursing Studies, 83, 18-24. https://doi.org/10.1016/j. ijnurstu.2018.04.005

Connor, J. (2016). Cultural influence on coping strategies of Filipino immigrant nurses. Workplace Health \& Safety, 64(5), 195-201. https:// doi.org/10.1177/2165079916630553

Cook, C., \& Brunton, C. (2018). The importance of moral emotions for effective collaboration in culturally-diverse healthcare teams. Nursing Inquiry, 25(2), e12214. https://doi.org/10.1111/nin.12214

De Chesnay, M. (2014). Nursing research using phenomenology: Qualitative designs and methods in nursing. New York, NY: Springer.

Drogendijk, R., \& Slangen, A. (2006). Hofstede, Schwartz, or managerial perceptions? The effects of different cultural distance measures on establishment mode choices by multinational enterprises. International Business Review, 15(4), 361-380. https://doi. org/10.1016/j.ibusrev.2006.05.003

Findyartini, A., Hawthorne, L., McColl, G., \& Chiavaroli, N. (2016). How clinical reasoning is taught and learned: Cultural perspectives from the University of Melbourne and Universitas Indonesia. BMC Medical Education, 16, 185. https://doi.org/10.1186/s12909-016-0709-y

Garneau, A. B., \& Peplin, J. (2015). Cultural competence: A constructivist definition. Journal of Transcultural Nursing, 26(1), 9-11. https://doi. org/10.1177/1043659614541294

Hardcastle, M. (2018). The importance of cultural fit in the success of internationally qualified nurses: A comment on Brunton \& Cook (2018). International Journal of Nursing Studies, 87, 148. https://doi. org/10.1016/j.ijnurstu.2018.08.001

Hofstede, G. (1980). Culture's consequences: International differences in work-related values. Beverly Hills, CA: Sage Publications.

Hofstede, G. (1991). Cultures and organizations: Software of the mind. London, UK: McGraw-Hill.

Hofstede, G. (2001). Culture's consequences: Comparing values, behaviors, institutions and organizations across nations, 2nd ed. Thousand Oaks, CA: Sage Publications.

Hofstede, G. (2011). Dimensionalizing cultures: The Hofstede model in context. Online Readings in Psychology and Culture, 2(1), 8. https://doi. org/10.9707/2307-0919.1014

House, R. J., \& Javidan, M. (2004). Overview of GLOBE. In R. J. House, P. J. Hanges, M. Javidan, P. W. Dorfman, \& V. Gupta (Eds.), Culture, leadership, and organizations: The GLOBE study of 62 societies (pp. 513-563). Thousand Oaks, CA: Sage Publications.

Hunter, K., \& Cook, C. (2018). Role-modelling and the hidden curriculum: New graduate nurses' professional socialisation. Journal of Clinical Nursing, 27(15-16), 3157-3170. https://doi.org/10.1111/ jocn.14510

Javidan, M. D., Luque, P., Sully, M., \& House, R. J. (2006). In the eye of the beholder: Cross cultural lessons in leadership from Project GLOBE. Academy of Management Perspectives, 20(1), 67-90. https://doi. org/10.5465/AMP.2006.19873410

Jenkins, B., \& Huntington, A. (2015). A missing piece of the workforce puzzle. The experiences of internationally qualified nurses in New Zealand: A literature review. Contemporary Nurse, 51(2-3), 220-231. https://doi.org/10.1080/10376178.2016.1158079

Johnson, S., Green, J., \& Maben, J. (2014). A suitable job? A qualitative study of becoming a nurse in the context of a globalizing profession in India. International Journal of Nursing Studies, 51(5), 734-743. https://doi.org/10.1016/j.ijnurstu.2013.09.009

Khalili, H., Ramji, Z., Mitchell, J., \& Raymond, G. (2015). Transition supports for IENs in workplace: Perspectives of IENs in Ontario. Journal of Nursing and Health Care, 2(2), 66-70. https://doi. org/10.5176/2010-4804_2.2.79 
Kim, M. (2010). Intercultural communication in Asia: Current state and future prospects. Asian Journal of Communication, 20(2), 166-180. https://doi.org/10.1080/01292981003693351

Kreitner, R., \& Kinicki, A. (2007). Organizational behavior, 7th ed. New York, NY: McGraw-Hill/Irwin.

Liamputtong, P. (2009). Qualitative research methods. South Melbourne, Vic: Oxford University Press.

Liamputtong, P. (2010). Preforming qualitative cross-cultural research. Cambridge, UK: Cambridge University Press.

Loh, M. I., Restubog, S. L. D., \& Zagenczyk, T. J. (2010). Consequences of workplace bullying on employee identification and satisfaction among Australians and Singaporeans. Journal of Cross-Cultural Psychology, 41(2), 236-252. https://doi.org/10.1177/0022022109354641

McSweeney, B. (2002). Hofstede's model and national cultural differences and their consequences: A triumph of faith - a failure of analysis. Human Relations, 55(1), 89-118. https://doi. org $/ 10.1177 / 0018726702551004$

Montayre, J., Montayre, J., \& Holroyd, E. (2018). The global Filipino nurse: An integrative review of Filipino nurses' work experiences. Journal of Nursing Management, 26(4), 338-347. https://doi.org/10.1111/ jonm.12552

Morrow, G., Rothwell, C., Burford, B., \& Illing, J. (2013). Cultural dimensions in the transition of overseas medical graduates to the UK workplace. Medical Teacher, 35(10), e1537-e1545. https://doi.org/10.310 9/0142159X.2013.802298

Mossop, L., Dennick, R., Hammond, R., \& Robbé, I. (2013). Analysing the hidden curriculum: Use of a cultural web. Medical Education, 47(2), 134-143. https://doi.org/10.1111/medu.12072

Mowat, R., \& Harr, J. (2018). Sacrifices, benefits and surprises of internationally qualified nurses migrating to New Zealand from India and the Philippines. Nursing Praxis in New Zealand, 34(3), 18-31.

Nursing Council of New Zealand (2013). The future nursing workforce: Supply projections 2010-2035. Retrieved from: http://www.nursingcouncil.org.nz/News/The-Future-Nursing-Workforce.

Nursing Council of New Zealand (2016). Annual report 2016. Wellington, New Zealand: Nursing Council of New Zealand.

Nursing Council of New Zealand. (n.d.). Competence assessment programmes. Retrieved from: http://www.nursingcouncil.org.nz/ Education/Competence-assessment-programmes.

Philip, S., Manias, E., \& Woodward-Kron, R. (2015). Nursing educator perspectives of overseas' qualified nurses' intercultural clinical communication: Barriers, enablers and engagement strategies. Journal of Clinical Nursing, 24(17-18), 2628-2637. https://doi.org/10.1111/jocn.12879

Philip, S., Woodward-Kron, R., Manias, E., \& Noronha, M. (2019). Overseas qualified nurses' (OQNs) perspectives and experiences of intraprofessional and nurse-patient communication through a Community of Practice lens. Collegian, 26(1), 86-94. https://doi. org/10.1016/j.colegn.2018.04.002

Pringle, J., Drummond, J., McLafferty, E., \& Hendry, C. (2011). Interpretative phenomenological analysis: A discussion and critique. Nurse Researcher, 18(3), 20-24. https://doi.org/10.7748/ nr2011.04.18.3.20.c8459

Ramji, Z., \& Etowa, J. (2018). Workplace integration: Key considerations for internationally educated nurses and employers. Administrative Sciences, 8(2), 1-18. https://doi.org/10.3390/admsci8010002

Riden, H., Jacobs, S., \& Marshall, B. (2014). New Zealand nurses' views on preceptoring international nurses. International Nursing Review, 61(2), 179-185. https://doi.org/10.1111/inr.12087

Sherwood, G., \& Shaffer, F. (2014). The role of internationally educated nurses in a quality, safe workforce. Nursing Outlook, 62(1), 46-52. https://doi.org/10.1016/j.outlook.2013.11.001

Sivakumar, K., \& Nakata, C. (2001). The stampede toward Hofstede's framework: Avoiding the sample design pit in cross-cultural research. Journal of International Business Studies, 32(3), 555-574. https://doi. org/10.1057/palgrave.jibs.8490984
Smith, P. B. (2002). Culture's consequences: Something old and something new. Human Relations, 55(1), 119-135. https://doi. org/10.1177/0018726702551005

Tie, Y. C., Birks, M., \& Mills, J. (2018). The experiences of internationally qualified registered nurses working in the Australian healthcare system: An integrative literature review. Journal of Transcultural Nursing, 29(3), 274-284. https://doi.org/10.1177/1043659617723075

Timilsina Bhandari, K. K., Xiao, L. D., \& Belan, I. (2014). Job satisfaction of overseas-qualified nurses working in Australian hospitals. International Nursing Review, 62(1), 64-74. https://doi.org/10.1111/ inr.12146

Timmons, S., Evans, C., \& Nair, S. (2016). The development of the nursing profession in a globalised context: A qualitative case study in Kerala, India. Social Science \& Medicine, 166, 41-48. https://doi. org/10.1016/j.socscimed.2016.08.012

Tregunno, D., Peters, S., Campbell, H., \& Gordon, S. (2009). International nurse migration: U-turn for a safe workplace transition. Nursing Inquiry, 16(3), 182-190. https://doi.org/10.1111/j.1440-1800.2009.00448.x

Tuttas, C. (2015). Perceived racial and ethnic prejudice and discrimination experiences of minority migrant nurses: A literature review. Journal of Transcultural Nursing, 26(5), 514-520. https://doi. org/10.1177/1043659614526757

Van Oudenhoven, J. P. (2001). Do organizations reflect national cultures? A 10-nation study. International Journal of Intercultural Relations, 25, 89-107. https://doi.org/10.1016/S0147-1767(00)00044-4

Verma, A., Griffin, A., Dacre, J., \& Elder, A. (2016). Exploring cultural and linguistic influences on clinical communication skills: A qualitative study of international medical graduates. BMC Medical Education, 16, 162. https://doi.org/10.1186/s12909-016-0680-7

Viken, B., Solum, E., \& Lyberg, A. (2018). Foreign educated nurses' work experiences and patient safety: A systematic review of qualitative studies. Nursing Open, 5(4), 455-468. https://doi.org/10.1002/ nop2.146

Wang, C., \& Greenwood, K. (2015). Chinese nursing students' culture-related learning styles and behaviours: A discussion paper. International Journal of Nursing Sciences, 2(3), 253-258. https://doi.org/10.1016/j. ijnss.2015.07.009

Willis, E. M., \& Xiao, L. (2014). Liminality, the Australian State and Asian nurse immigrants. Health, Culture and Society, 6(1), 32-46. https:// doi.org/10.5195/hcs.2014.118

Xu, Y. (2010). Transitioning international nurses: An outlined evidencebased program for acute care settings. Policy, Politics, \& Nursing Practice, 11(3), 202-213. https://doi.org/10.1177/1527154410384879

Xu, Y., Gutierrez, A., \& Kim, S. H. (2008). Adaptation and transformation through (un)learning: Lived experiences of immigrant Chinese nurses in US healthcare environment. Advances in Nursing Science, 31(2), e33-e47. https://doi.org/10.1097/01.ANS.0000319570.99254.e5

Yan, J., \&Hunt, J. G. (2005). A cross cultural perspective on perceivedleadership effectiveness. International Journal of Cross Cultural Management, 5(1), 49-66. https://doi.org/10.1177/1470595805050824

Zhou, Y., Windsor, C., Theobald, K., \& Coyer, F. (2011). The concept of difference and the experience of China-educated nurses working in Australia: A symbolic interactionist exploration. International Journal of Nursing Studies, 48(11), 1420-1428. https://doi.org/10.1016/j. ijnurstu.2011.05.003

How to cite this article: Choi MS, Cook CM, Brunton MA.

Power distance and migrant nurses: The liminality of acculturation. Nurs Inq. 2019;26:e12311. https://doi. org/10.1111/nin.12311 


\section{Power distance and migrant nurses: The}

\section{liminality of acculturation}

Choi, MS

2019-10

22/04/2023 - Downloaded from MASSEY RESEARCH ONLINE 